\title{
The automatic and manual railroad door systems based on IoT
}

\author{
Setiyo Budiyanto ${ }^{1}$, Freddy Artadima Silaban ${ }^{2}$, Lukman Medriavin Silalahi $^{3}$, Triyanto Pangaribowo ${ }^{4}$, \\ Muhammad Hafizd Ibnu Hajar ${ }^{5}$, Alvin Sepbrian ${ }^{6}$, Rachmat Muwardi ${ }^{7}$, Gao Hongmin ${ }^{8}$ \\ 1,2,3,4,5 Department of Electrical Engineering, Universitas Mercu Buana, Jakarta, Indonesia \\ ${ }^{6}$ Department of Instrument Design Engineering PT. Rekayasa Engineering, Jakarta Selatan, Indonesia \\ ${ }^{7,8} \mathrm{School}$ of Information and Electronics, Beijing Institute of Technology, Beijing, China
}

\begin{tabular}{l} 
Article Info \\
\hline Article history: \\
Received Oct 11, 2020 \\
Revised Dec 13, 2020 \\
Accepted Dec 27, 2020 \\
\hline
\end{tabular}

\section{Keywords:}

Arduino

Infrared

Railway door crossing

Web server

\begin{abstract}
The automatic and manual IoT-based rail door (internet of things) is a door bar designed to be able to close and open automatically and manually. The automatic system works based on sensors that detect the presence of trains and system manual works based on the open and Close button on the smartphone. The components to be used are ATmega328 microcontrollers, Infrared sensors, power supply, CCTV and android applications. Infrared sensor will detect the presence of the train and the gate will close automatically. Then the doorway will open when the train has crossed the automatic door bar. By the manual way, rail door control can be open and closed with android smartphones in real-time with graphical display provided by CCTV. The whole process is connected to a WEB server where the program is embedded. Either it is automatic or manual control. From the tests that have been done, that the response data from the server is very fast, which is less than 1 second civil. For Infrared Sensor 1 There is an average delay of $0,687 / \mathrm{sec}$ and Infrared Sensor 2 is 3,449/sec. In realtime CCTV There is an average delay of $0,857 / \mathrm{sec}$.
\end{abstract}

This is an open access article under the CC BY-SA license.

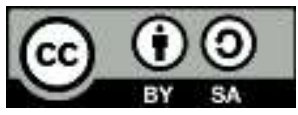

\section{Corresponding Author:}

Freddy Artadima Silaban

Department of Electrical Engineering

Universitas Mercu Buana

Meruya Selatan, Kembangan, Jakarta Barat 11650, Indonesia

Email: freddy.artadima@mercubuana.ac.id

\section{INTRODUCTION}

The The rapid development of technology makes the technology began to be widely applied in various fields. In everyday life, many new technologies have been enabled. This is because implementing innovations using the latest technology will make human work easier than it needs to be done manually.

Using an automated system or robotics based on IoT (internet of things) is expected to reduce human performance. One of the applications of technology can be done on the railway gate sector. Manually, the train door crossing is controlled by one person per the hatch. And for a day, it requires at least three people to control the train's doorway manually [1-5]. This is less effective and less efficient where in some places railroad crossings often occur accidents, due to several factors namely the unprepared staff of the doorstop when long-distance trains are crossing with conditions of late communication signals, the system used does not support automatically giving a warning. According to various sources of information, both print and electronic media, there are many intersections throughout the railroad tracks in Indonesia, many of which do not have both manual and automatic doorstop, this is very dangerous if observing along the railroad lines is a community settlement [6-11]. 
It is not a new thing in the world of transportation technology. As for the already applied in the transportation world, the toll gate Manual is migrated to the automatic toll gate using RFID and also monitored in real-time by CCTV [12-18]. Therefore, the authors have the idea of creating a miniature automatic railway door that is based on IoT, with the formulation of the problem that is how to design and make a miniature automatic doorstop at the crossing of the flame, how to open and close the doorstop automatically and manually based on IoT, and how to use Android Studio Software to design real-time display and manual control buttons on smarphone [19-25]. This tool is expected to reduce human performance so that one person can monitor and control several rail gates automatically and manually using IoT.

\section{RESEARCH METHOD}

\subsection{Block diagram}

Before determining and making hardware, first done planning block diagram that will be the framework of reference in making application tools as desired. The diagram block of the system is found in Figure 1. The result of Figure 1 is a diagram block from the system settings. Broadly, the system is divided into three parts: input, process data/program, and output. The input section consists of Infrared and CCTV Camera. Meanwhile, the output consists of servo Motor as the Mobilizer and Buzzer. As for the process of using an ATmega microcontroller 328 combined with the W5100 Ethernet module, it is used as the main control for processing data programs. Switch Hub and Router are used as Monitoring and control globally with the Internet. This tool is designed with controlling process flow. Control begins with the identification process, which is the input of data in the form of Infrared inputs when detecting the presence of passing trains, inputs in the form of indications that there is a train sent to the microcontroller. If the data is valid, the microcontroller will provide an execution order to the servo motor to open the train door bar. As for the manual way, CCTV will display the train door crossbar in real-time in mobile Android where the tone of the settings buttons open close the train door manually and can be moved automatically.

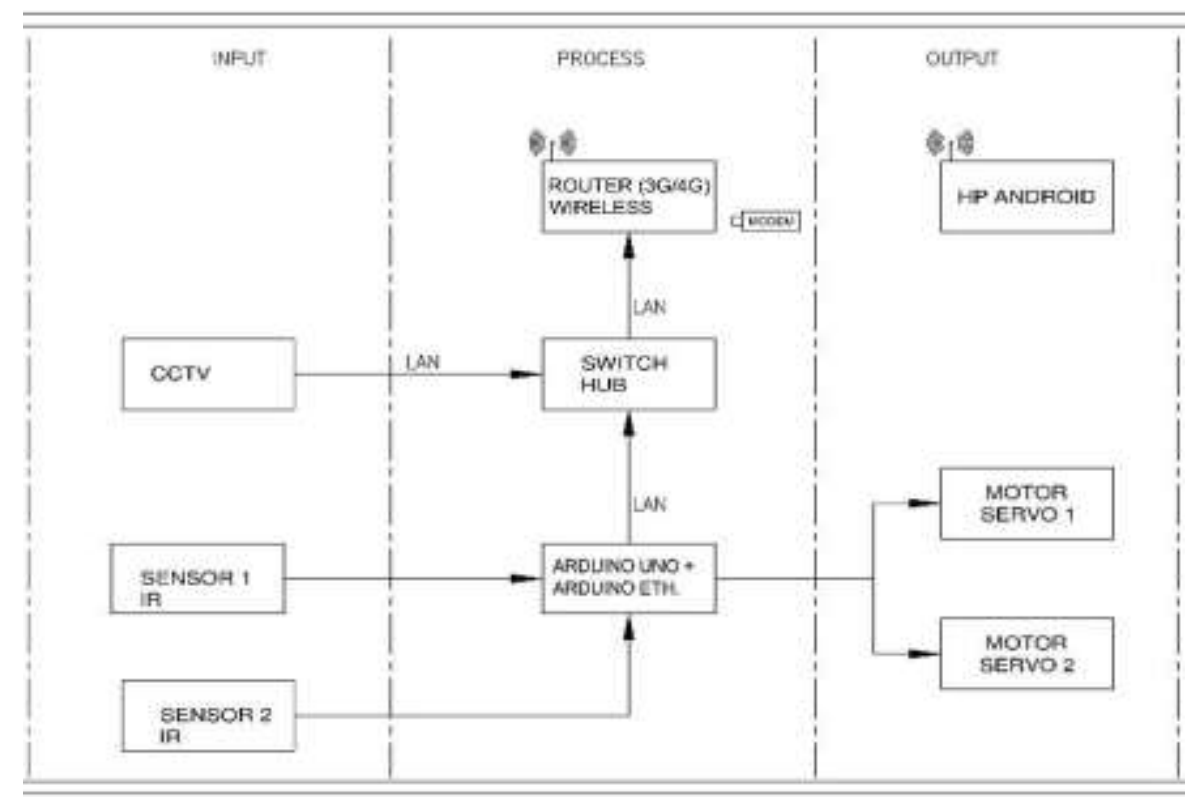

Figure 1. Block diagram system

\subsection{Electrical design}

In the design and manufacture of IoT-based automatic and manual rail door tools, in addition to using Arduino Uno as the main control, it also uses other components as supporting components. In Figure 2 above is an electronic design consisting of components such as the Arduino Shield microcontroller, CCTV camera, servo motor, internet modem, switch hub, buzzer, and smartphone. These components are integrated to form a system design for railroad crossings. 


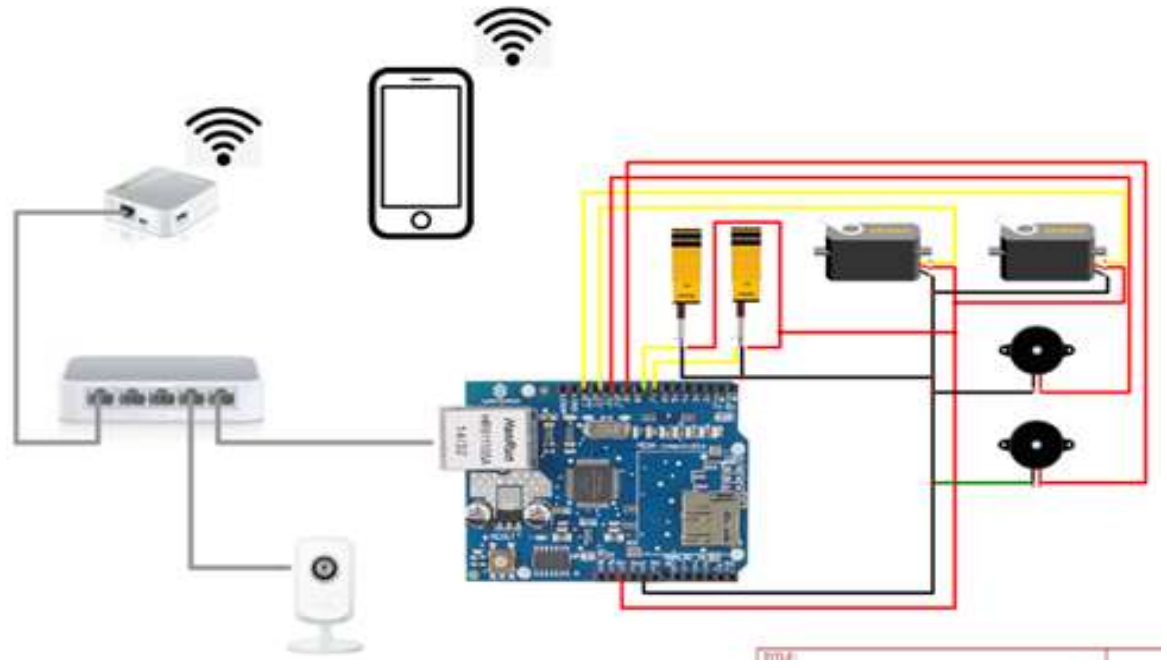

Figure 2. Electronic design

\subsection{Software design}

Scaffolding software includes program creation and design. Inside this final assignment, authors use Arduino IDE and Android Studio as a program and design. Programming is generally done at the final stage, after the mechanical and electrical design is completed. Because in the process of programming on the programmers is done by testing way. So to do so the device component must be able to be upgraded. Programming is to include information or code (coding) into a microcontroller. Where it is expected that ALA can operate under the will of its election or initial planning before being made.

\subsubsection{Infrared sensor program}

This software programming discussed in the planning phase of the software using the Arduino software. The purpose of this software design as in Figure 3 is to facilitate the programming that will be inserted or implanted into Arduino Uno using Arduino software.

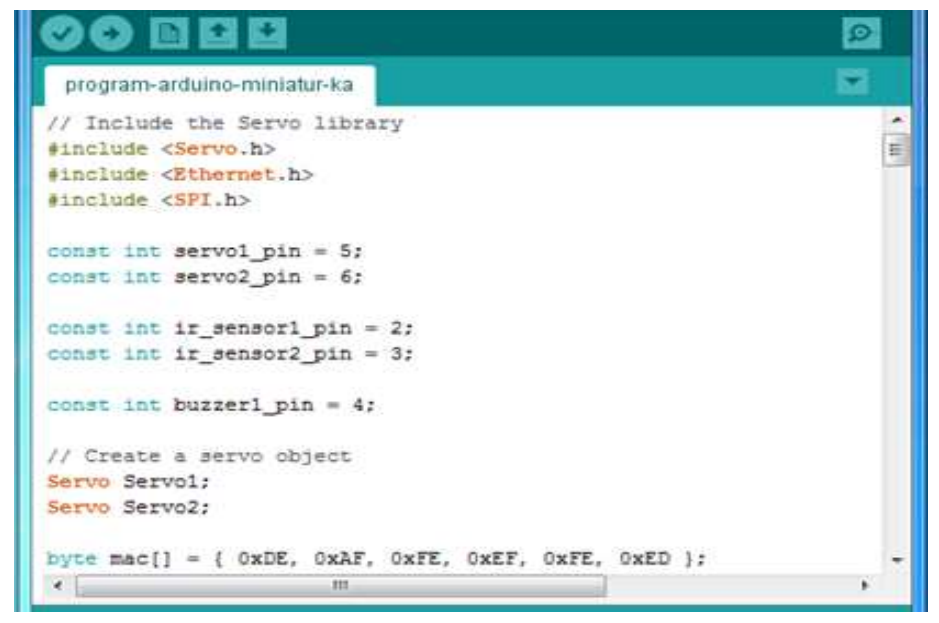

Figure 3. Infrared sensor program

\subsubsection{Android studio programming}

The purpose of this software design is to facilitate the programming and design that will be used to display real-time video from CCTV that has been installed and to control the railway door manually through mobile Android. Figure 4 is the coding place to display the commands by the design and program created. The output format of this app is in the form of an apk that can run on Operating Android-based systems. 


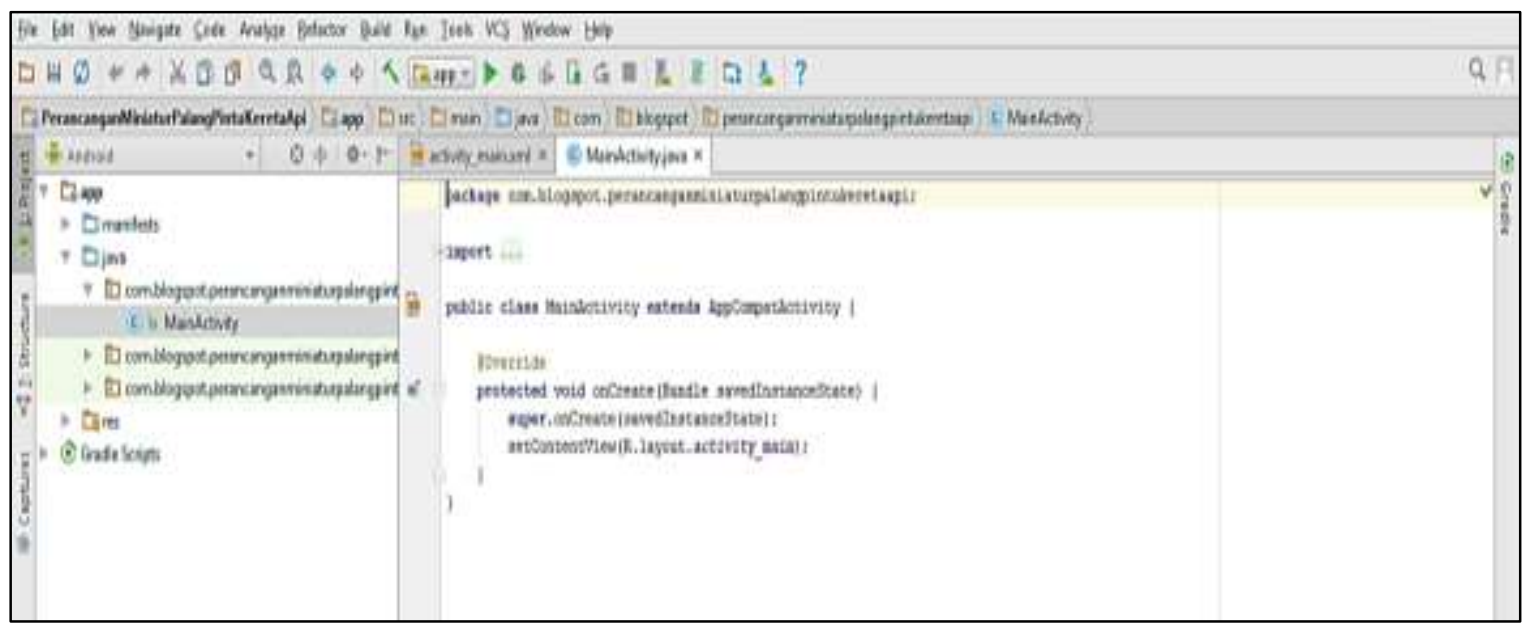

Figure 4. Design view mainActivity.java

\section{RESULTS AND DISCUSSION}

Testing tools are conducted to determine the performance of the tool and know the results through analysis. The things that will be tested include the overall work testing tool, voltage testing on the appliance, Infrared testing, Servo Motor as an automatic drive of the railway Gate and Android Mobile as the car's doorway manually driven (internet of things). Next, the entire device testing phase of the Interlock system on automatic and manual gate access with Infrared identification will then provide input on the servo motor to seal the train door. After performing the design of the system and making the tool, obtained the result of a miniature automatic and manual Crossdoor tool, there is the most important tool component in this tool as in Figures 5, 6 and 7.

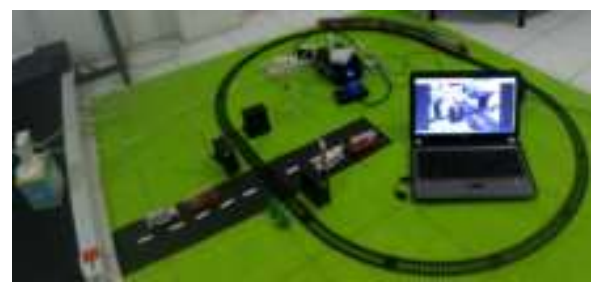

Figure 5. Railway system

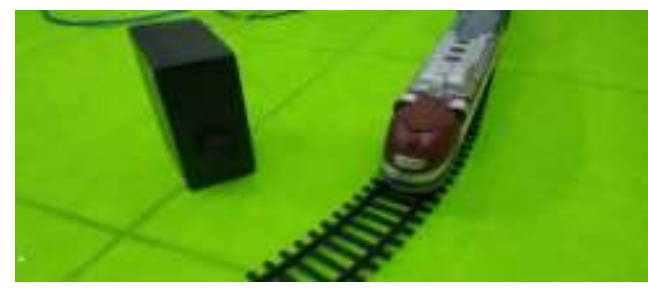

Figure 6. Infrared system

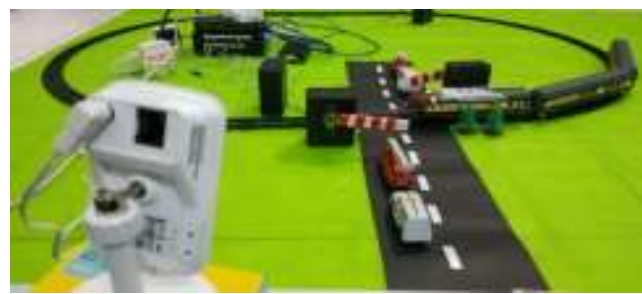

Figure 7. Railway door closing

The result of the third image above is the component of the Birthpoint tool and the main tool component used in the process of the tool. The job description of all tool components. The explanations of each section are as follows:

a) Automated process, infrared is placed in the section before the train door as a detector or reader when the train passes. When Infrared detects a car, the door of the train will close and open the door, Infrared will send data to the controller to be identified. When the data is valid, the controller will emit output to keep the door closed and open using the servo motor. Manual process, the controller will send IP statically to 
the global server in order to access via global network or internet bass and will be displayed with Android Smartphone media in the form of CCTV camera and servo motor drive button or the railway door.

b) Infrared is used as a media detector where doors will open or close

c) Microcontroller series as brain data processing and controlling center.

d) Servo Motor as an automatic gate drive.

e) Web Server as a global network to manually control the door of the train and also display it via CCTV.

f) Smartphone Android as a manual drive media and monitoring the railway door with CCTV.

g) Miniature trains on Autorun with battery.

Once all the parts are installed and integrated well, the next thing to do is to do the test. Tool testing is done gradually section by section to see if the part can work fine before testing the tool as a whole. The sections to be tested will be discussed in the sub-chapter below.

\subsection{Transmitting data test}

The Data transmission in Figure 8 is the result of microcontroller communication with the web server featured in the arduino serial monitor. In Figure 8 shows data traffic between microcontrollers requesting data and responsive Web Server. To clarify data delivery time in Figure 8 can be seen in the following Table 1.

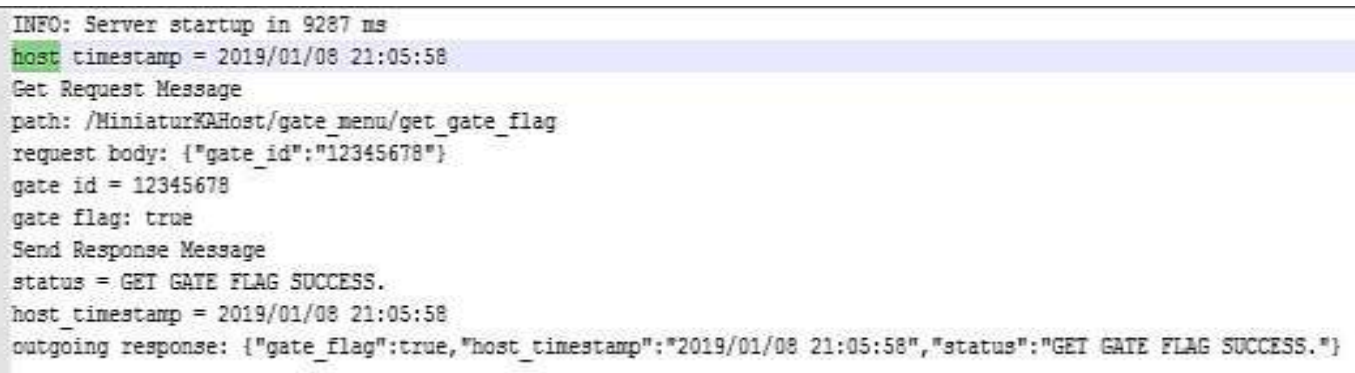

Figure 8. Data status

Table 1. Transmitting data test

\begin{tabular}{|c|c|c|c|}
\hline No & Start & Respons & Description \\
\hline 1. & $\begin{array}{c}\text { host timestamp }= \\
\text { 2019/01/08 21:05:58 } \\
\text { Get Request Message }\end{array}$ & $\begin{array}{c}\text { host_timestamp }=2019 / 01 / 08 \text { 21:05:58 } \\
\text { outgoing response: }\{\text { "gate_flag":true,"host_timestamp":"2019/01/08 } \\
\text { 21:05:58","status":"GET GATE FLAG SUCCESS."\} }\end{array}$ & $\begin{array}{l}\text { Response from Web Server } \\
\text { less than } 1 \text { second }\end{array}$ \\
\hline 2. & $\begin{array}{l}\text { host timestamp }= \\
\text { 2019/01/08 21:06:07 }\end{array}$ & $\begin{array}{r}\text { host_timestamp }=2019 / 01 / 08 \text { 21:06:07 } \\
\text { outgoing response: \{"gate_flag":true,"host_timestamp":"2019/01/08 }\end{array}$ & $\begin{array}{l}\text { The response from the Web } \\
\text { Server is the same. Same }\end{array}$ \\
\hline 3. & $\begin{array}{l}\text { Get Request Message } \\
\text { host timestamp }= \\
\text { 2019/01/08 21:06:08 } \\
\text { Get Request Message }\end{array}$ & $\begin{array}{l}\text { 21:06:07","status":"UPDATE GATE FLAG SUCCESS." } \\
\text { host_timestamp = 2019/01/08 21:06:08 } \\
\text { outgoing response: \{"gate_flag":true,"host_timestamp":"2019/01/08 } \\
\text { 21:06:08","status":"GET GATE FLAG SUCCESS."\} }\end{array}$ & $\begin{array}{l}\text { request distance. } \\
\text { The response from the Web } \\
\text { Server is the same. Same } \\
\text { request distance. }\end{array}$ \\
\hline
\end{tabular}

The result of the Table 1 shows that data transmission is very consistent and fixed i.e. every 1 second per data. The Web Server responds less than 1 second to any data transmission done in the table above.

\subsection{Infrared test}

Infrared is a tool or a sensor that is installed before the automatic door bar. The Infrared works following the functions in general without experiencing any reshuffle and modification of the slightest. To perform an infrared response data picker, this Sensor is installed before the train door that will then provide data input to close and unwell the train or servo motor doors.

The result of the above Table 2 and Table 3 shows that Infrared 1 gives the signal to the servo to close the gate of the average train takes time: $0,685+0,675+0,648+0,757+0,669=3,434: 5=0,687$ /second. On Infrared 1, the System program does not use the delay at all. On Infrared 2 gives the signal to the servo to open the gate of the average train takes time : 3,526+3,286+3,486+3,710+3,235=17,243:5= 3,449 /second. On Infrared 2, program on the system using the delay 1,5 second. 


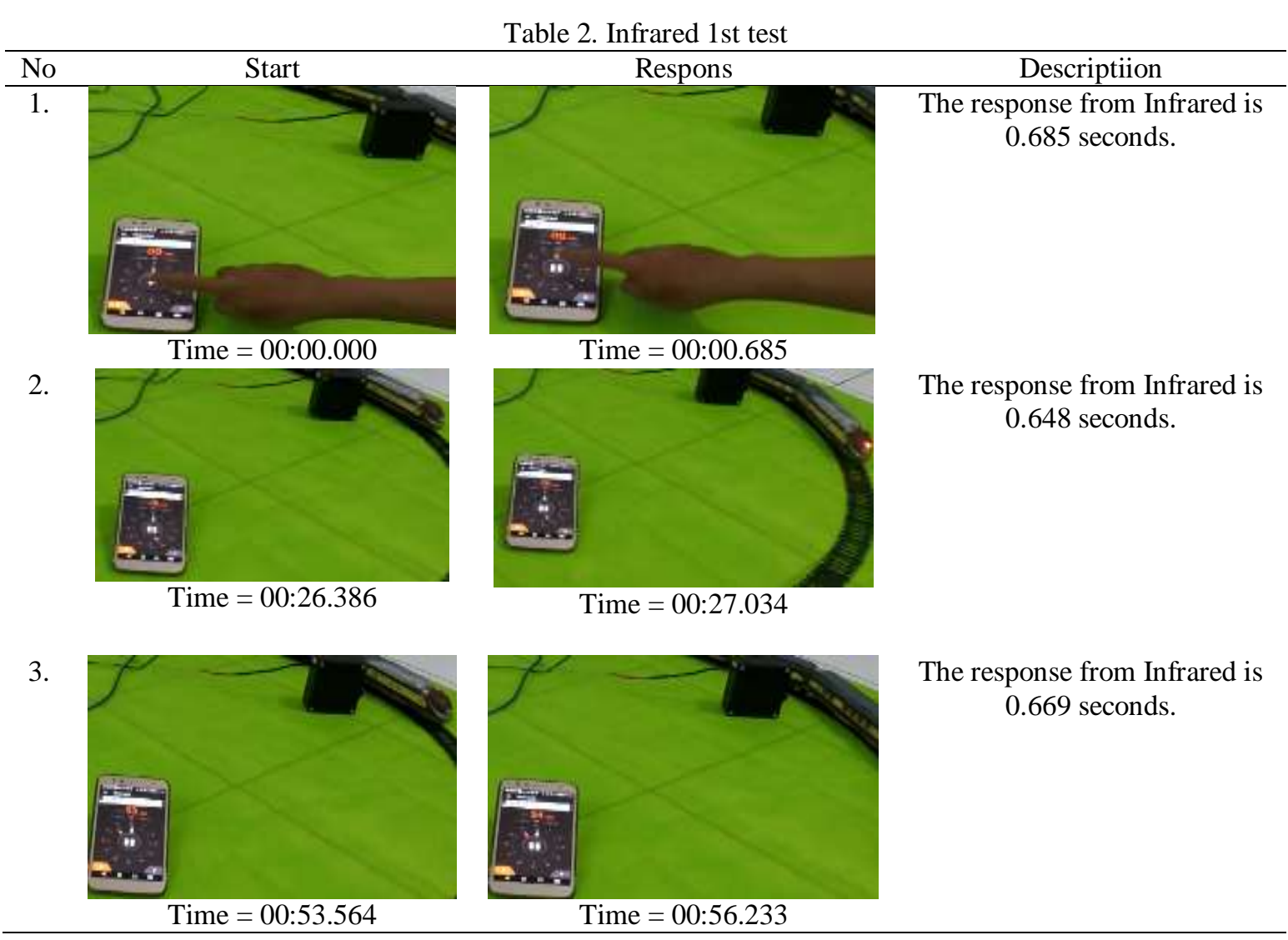

Table 3. Infrared 2nd test

2.




\subsection{CCTV test}

CCTV here is a tool for realtime monitoring of the railway door. The CCTV works the following functions in general without experiencing any reshuffle and modification. To perform the CCTV response data maker, CCTV is installed around the railway door that will give a graphical display that will be displayed in realtime. The result of the above Table 4 shows that CCTV displays realtime graphics on the average rail door takes time: $0,678+0,930+0,889+0,858+0,927=3,434: 5=0,857 /$ second, On this CCTV, the delay of graphics displayed depends on the high and low Internet bandwidth gained. Because the whole system runs with an Internet connection to communicate with the Web Server.

Table 4. CCTV test

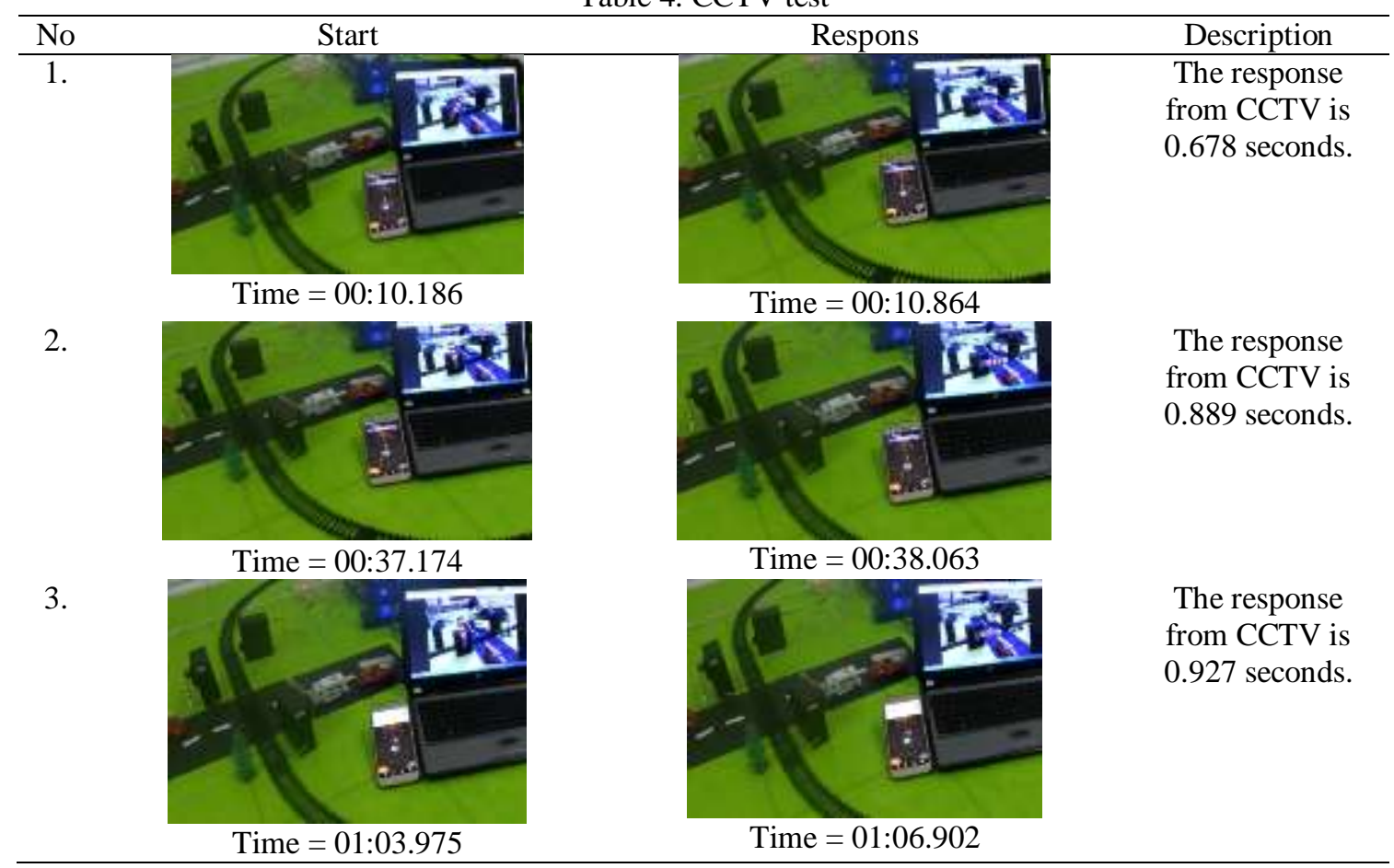

\section{CONCLUSION}

From the designing and manufacturing of miniature automatic and manual rail doors to the train crossing to produce a work result. Then this can be taken the following conclusions, the tests that have been done, that the response data from the server is very fast, which is less than 1 second civil. For infrared sensor 1 , there is an average delay of $0,687 / \mathrm{sec}$ and Infrared Sensor 2 is 3,449/sec. In realtime CCTV There is an average delay of $0,857 / \mathrm{sec}$.

\section{REFERENCES}

[1] Singh, R. S. S., Ibrahim, A. F. T., Salim, S. I. M., \& Chiew, W. Y.”Door Sensors for Automatic Light Switching System" in 2009 Third UKSim European Symposium on Computer Modeling and Simulation, doi:10.1109/ems.2009.75, 2009.

[2] Nishida, D., Tsuzura, K., Kudoh, S., Takai, K., Momodori, T., Asada, N.Tomizawa, T.”Development of Intelligent Automatic Door System" in 2014 IEEE International Conference on Robotics and Automation (ICRA), doi:10.1109/icra.2014.6907799, 2014.

[3] Tsai, C.-H., Bai, Y.-W., Chen, P.-C., Jhang, R. J. R., \& Lin, M.-B.”Reduction of the standby power consumption of an automatic door system" in 2016 IEEE International Conference on Consumer Electronics (ICCE), doi:10.1109/icce.2016.7430739, 2016.

[4] Liu, C., Kong, L., Cao, Y., \& Huang, Q.”Motion States Recognition System Based on Ultrasound for Automatic Door Management" in 2011 International Conference on Internet Computing and Information Services, doi:10.1109/icicis.2011.10,2011.

[5] Jing, C.'Design of a New Type of Automatic Cage Door with Hydraulic Drive" in 2018 11th International Conference on Intelligent Computation Technology and Automation (ICICTA), doi:10.1109/icicta.2018.00084, 2018.

[6] Rachmawati, A. L. Nugraha, and M. Awaluddin."Desain Aplikasi Mobile Informasi Pemetaan Jalur Batik Solo Trans Berbasis Android Menggunakan Location Based Service" in Jurnal, Universitas Diponegoro, 2017. 
[7] M. A. Firdaus and A. B. Utomo."Miniatur Palang Pintu Kereta Api Otomatis dengan Menampilkan Kecepatan Kereta Serta Waktu Tunggu Menggunakan Arduino" in Jurnal, Universitas Negeri Semarang, 2016.

[8] B. Amos, B. Ludwiczuk, M. Satyanarayanan."Openface: A general-purpose face recognition library with mobile applications" in CMU-CS-16-118, CMU School of Computer Science, Tech. Rep., 2016.

[9] Setiyo Budiyanto and Arrissetyanto Nugroho."A New Model Of Genetic Zone Routing Protocol (GZRP): The Process Of Load Balancing and Offloading on the UMTS-IEEE 802.11g Hybrid Network" in TELKOMNIKA (Telecommunication, Computing, Electronics and Control), vol. 15, no. 2, pp.598-605, 2017.

[10] Zhanshun Yin, \& Jinshui Shi."Ventilation Door's Automatic Control System Based on PLC and Rotary Encoder" in 2013 Fifth International Conference on Measuring Technology and Mechatronics Automation, doi:10.1109/icmtma.2013.319, 2013.

[11] Freddy Artadima Silaban, Setiyo Budiyanto, and Wahyu Kusuma Raharja."Stepper motor movement design based on FPGA, “ in International Journal of Electrical and Computer Engineering (IJECE), vol. 10, no. 1, February 2020, pp. 151-159, 2020.

[12] Nath, S., Banerjee, P., Biswas, R. N., Mitra, S. K., \& Naskar, M. K., ”Arduino based door unlocking system with real time control" in 2016 2nd International Conference on Contemporary Computing and Informatics (IC3I), doi:10.1109/ic3i.2016.7917989, 2016.

[13] Yong-Su Kirn, Sung Hong Won, Jun Sun Ahn, You Young Choe, Young Guan Kim, Chang Hyun Cho,...Ju Lee. "Analysis of the linear DC motor for the automatic door system," in 2005 International Conference on Electrical Machines and Systems, doi:10.1109/icems.2005.202524,2005.

[14] Budiyanto, S., Asvial, M., \& Gunawan, D, "Implementation of genetic zone routing protocol (GZRP) in 3G-WiFi Offload Multi Base Station," 2013 IEEE International Conference of IEEE Region 10 (TENCON 2013). doi:10.1109/tencon.2013.6718859, 2013.

[15] Sumbul, H., Coskun, A., \& Tasdemir, M., "The control of an automatic door using fuzzy logic" in 2011 International Symposium on Innovations in Intelligent Systems and Applications, doi:10.1109/inista.2011.5946111, 2011.

[16] Setiyo Budiyanto, Muhammad Asvial, Dadang Gunawan.'Performance Analysis of Genetic Zone Routing Protocol Combined with Vertical Handover Algorithm in 3G - WiFi Offload," in Journal of ICT Research and Applications, vol. 8 no. 1 pp. 49-63, 2014.

[17] N. Azaliah, A. Bakar, W. Makhtariah, W. Ramli, and N. H. Hassan, "The internet of things in healthcare: anoverview, challenges and model plan for security risks management process", vol. 15, no. 1, pp. 414-420, 2019.

[18] Setiyo Budiyanto, Galih Bangun Santosa and Fajar Rahayu Ikhwannul Mariati, "Upgrading the S-NCI Key Establishment Protocol Scheme to be Secure and Applicable" in IOP Conference Series: Materials Science and Engineering, vol. 454, 2018.

[19] K. Varma and V. V. Kumari, "A Security Framework for Ethernet Based Embedded Web Server" in International Journal of Embedded Systems and Applications (IJESA), vol. 2, no. 2, 2012.

[20] Setiyo Budiyanto, Beny Nugraha and Dian WidiAstuti,."Performance Test of Various Types of Antenna Arrays in Real Propagation Environment” in Institute of Physics Publishing (IOP) Conference Series: Materials Science and Engineering, vol. 105, no. 1, 2016.

[21] Wang, Z., \& Liu, L."Research on Linkage Control Strategy of Train Door and Platform Door Based on Automatic Driving Technology" in 2019 IEEE 3rd Information Technology, Networking, Electronic and Automation Control Conference (ITNEC), doi:10.1109/itnec.2019.8729537,2019.

[22] R. Muhendra, A. Rinaldi, M. Budiman, dan Khairurrijal."Development of WiFi Mesh Infrastructure for Internet of Things applications. Department of Physics" in Faculty of Mathematics and Natural Sciences, Institut Teknologi Bandung, EPIC 2016.

[23] Andi Juansyah."Pembangunan Aplikasi Child Tracker Berbasis Assisted - Global Positioning System (A-GPS) dengan Platform Android" in Jurnal Ilmiah Komputer dan Informatika (KOMPUTA), Edisi. 1 Volume. ISSN : 2089-9033, Universitas Komputer Indonesia, 2015.

[24] Adriansyah, Andi \& Ferdana, Nanda \& Budiyanto, Setiyo \& Andika, Julpri."Design of Telemedicine Robot using Behavior-based Control Architecture with Two-Step Fuzzy Logic Optimization” in Journal of Computer Science. vol. 15, pp. 1617-1626. 10.3844/jcssp.2019.1617.1626, 2019.

[25] Budiyanto, Setiyo; Sihombing, Harry Candra; Rahayu, Fajar I M, "Depression And Anxiety Detection Through The Closed-Loop Method Using DASS-21" in TELKOMNIKA(Telecommunication, Computing, Electronics and Control), vol. 17, no. 4, 2019.

\section{BIOGRAPHIES OF AUTHORS}

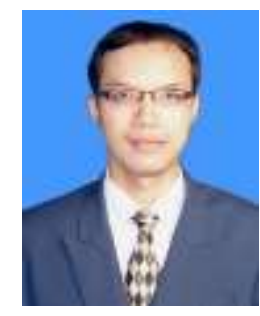

Setiyo Budiyanto is an Associate Professor in Electrical Engineering, Universitas Mercu Buana. He received his Ph.D in Electrical Engineering, Universitas Indonesia (2016). Currently he is active as a Lecturer at Universitas Mercu Buana, Jakarta (Indonesia). He conducts some research in the fields of Digital - Advanced Wireless Communication (D-AWC) 

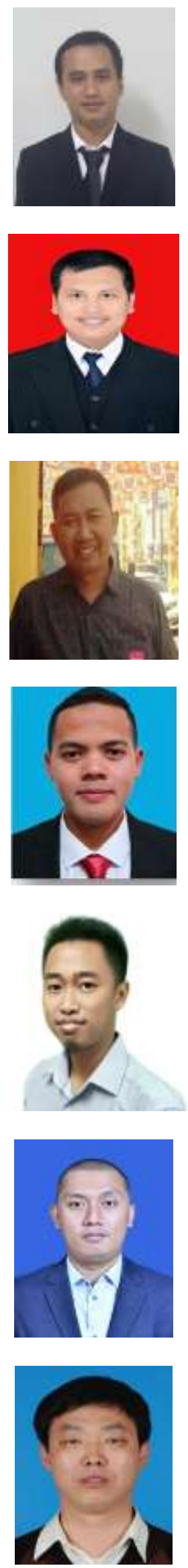

Freddy Artadima Silaban received his Master of Engineering (MT) degree in Electrical Engineering, Information Technology Specialization, Gunadarma University, Depok, 2016. He currently teaches at Universitas Mercu Buana, Jakarta (Indonesia). The focus of the research is an embedded system using control devices such as the FPGA, Arduino, and NodeMCU Modules. As well as IC design research using Xilinx ISE.

Lukman Medriavin Silalahi received his Master of Engineering (MT) degree in Electrical Engineering, Microwave Technology, Universitas Mercu Buana, Jakarta, 2017. He currently teaches at Universitas Mercu Buana, Jakarta (Indonesia). The focus of research is mobile telecommunications and embedded systems.

Triyanto Pangaribowo received his Master of Engineering (MT) degree in Electrical Engineering, Microwave Technology, Universitas Mercu Buana, Jakarta. He currently teaches at Universitas Mercu Buana, Jakarta (Indonesia).

Muhammad Hafizd is a lecturer in Electrical Engineering at Universitas Mercu Buana Jakarta. He completed his Master's degree at Beijing Institute of Technology, China in 2017. After graduating, he got the opportunity to become a teacher and do some research. The research topics involved are the field of Robotics and Electronics. In addition, he was also active in Community Service activities and became one of the journal's management team.

Alvin Sepbrian is Graduate Degree in Electrical Engineering, Universitas Mercu Buana. He received his S.T. in Electrical Engineering, Universitas Mercu Buana (2019). Currently he is active as an Engineer at PT. Rekayasa Engineering, Jakarta (Indonesia) with job description Instrument Design Engineering.

Rachmat Muwardi lecturer at Universitas Mercu Buana. He graduated from the Beijing Institute of Technology in 2020 with a Masters degree in Electronic Science and technology. At the time of undergraduate, he received a double degree scholarship from Universitas Mercu Buana and Beijing Institute of Technology in Electrical Engineering and Computer Science.

Gao Hongmin is a Professor, Postdoctoral of School of Information and Electronics, Beijing Institute of Technology. Major: Electronic Science and Technology, Control science and Engineering Main research direction: RF circuit design, Millimeter wave THz technology and system, Frequency Synthesis Technique, Navigation and Communication Technology. Memberships : Members of the group postdoctoral foundation of evaluation experts, Members of the group of Hebei Province Natural Science Fund Evaluation Experts, Cable radio and television programming group of experts. 